\title{
Special Issue in Memory of Murat R. Sertel
}

\author{
Semih Koray • Muhamet Yıldız
}

Published online: 14 November 2006

(C) Springer-Verlag 2006

Murat R. Sertel, the founding editor-in-chief of the Review of Economic Design, passed away on January 25, 2003, in Aix-en-Province, France due to a heart attack. He was a genuine scholar, a brilliant intellectual, an excellent teacher, an energetic entrepreneur, a beloved friend, an enthusiastic leader, a generous host, a wonderful company, a devoted son and an affectionate father. This man from the Bosphorus whose contributions to put Turkey on the academic map of economic theory have been tremendous was a special person for everyone who knew him. His untimely death was met with deep sorrow by his colleagues, friends and students from all over the world.

The Special Volume in Memory of Murat R. Sertel which starts with this issue will be reflecting the friendly atmosphere surrounding Murat's Memory as well as the broad intellectual spectrum of economic design to which Murat's contributions have been deep and comprehensive. Although Murat's work in economic theory covers a wide variety of topics, his vision of economic design can be traced from his earliest works to his latest studies, and can best be summarized by the following statement taken from the introduction of Advances in Economic Design (Murat R. Sertel, S.Koray (eds.) (2003), Springer):

"Every existing institution is one from among many possibilities, and in many cases it is very doubtful that the existing world is the best among all possible worlds that we could have had."

S. Koray $(\varangle)$

Department of Economics, Bilkent University, 06800 Bilkent, Ankara, Turkey

e-mail: ksemih@bilkent.edu.tr

M. Yildiz

Department of Economics, MIT, Cambridge, MA 02142-1347, USA

e-mail: myildiz@mit.edu 
The main focus of Murat's interest lay undoubtedly in designing rights. The design of any institution or any legal-economic instrument involves - implicitly in some instances or more explicitly in others - an arrangement or a rearrangement of power distribution. Having dealt with various instances of this in several different particular contexts, Murat's efforts culminated in the formulation and analysis of the concept of a Rechtsstaat, where the power distribution in a society is made explicit through a code of rights. This is a notion which all researchers in the Area of Economic Design will come across more and more frequently in the near future. The design of rights structures is surely the main common factor of all the papers that will appear in the Special Volume in Memory of Murat R. Sertel, although these cover a very wide range of areas otherwise.

A more detailed description of the topics that are covered by the Review of Economic Design can be found in the Aims and Scope of the journal, which was drafted by Murat himself. As the editors of this Special Volume, we are proud of announcing that the Special Volume in Murat's Memory solicited leading papers exemplifying each and every item listed the Journal's Aims and Scope. These include "constitutions and other assignments of rights, mechanisms for allocation or regulation, tax and incentive schemes, contract forms, voting and other choice aggregation procedures, markets, auctions, organizational forms, such as partnerships, together with supporting membership and other property rights, and information systems". 